\title{
Self-Ideal-Self Discrepancy as a Defensive Style
}

\author{
Jeffrey Binder, Martin Mayman, and Steven Doehrman
}

$\mathbf{T}$

HERE IS an assumption widely maintained in personality research that a large discrepancy between experienced self and ideal self reflects emotional disturbance, while its absence is a sign of emotional health. The most important and extensive clinical application of this assumption has been the $Q$-sort studies of Rogerian therapists postulating that productive change in therapy coincides with a decreasing discrepancy between experienced self and ideal self as more realistic relationships develop between one's attitudes and abilities and one's values and goals. ${ }^{1}$ This assumption was supported in several studies, in which some measure of self-ideal-self discrepancy was tested against some measure of adjustment. ${ }^{2-6}$

Just as often, however, researchers did not find the expected positive relationships between low self-ideal-self discrepancy and adjustment. Individual differences sometimes attenuated a hypothesized positive linear relationship. ${ }^{7}$ Chodorkoff 8 found "high-adjustment" subjects with both very low and very high self-ideal-self discrepancy scores. Several studies comparing paranoid schizophrenics, neurotics, and normals found that paranoid schizophrenics had selfideal-self discrepancy scores as low as or lower than normals. ${ }^{9-11}$ These authors reasoned that emotional adjustment would be directly reflected in a measure of realistic self-acceptance. They concluded that the low self-ideal-self discrepancy scores for their paranoid schizophrenic subjects reflected a defensive maneuver characterized by unrealistic self-enhancement. Ibelle ${ }^{11}$ in particular concluded that rather than providing a clear-cut measure of psychological health, the results of these studies suggest that the $Q$-sort self-ideal-self discrepancy may be an excellent indicator of the effectiveness of an individual's self-system in maintaining unacceptable aspects of the self in a state of dissociation, thus protecting the individual from experiences of severe anxiety and feelings of self-dissatisfaction.

After reviewing this second group of studies, it is reasonable to hypothesize that self-ideal-self discrepancy is related to a defensive style involving the manner in which self-dissatisfaction is handled. Indeed, at least two studies have supported this notion. Self-ideal-self discrepancy was tested against overcontrollers-undercontrollers ${ }^{12}$ and repressors-sensitizers. ${ }^{13}$ Both of these dimensions contrast a style of handling conflict by avoiding it through denial and projection versus a style using isolation and intellectualization to obsessively mull over conflicts. In both studies, a significant positive association was found between low self-ideal-self discrepancy and the avoidant style characteristic of overcontrollers and repressors.

The two studies reported below represent an attempt to further test the hypothesis that the measured discrepancy between experienced self and ideal self is related to defensive style; it reflects a disposition to accentuate or to hide self-

From the Neuropsychiatric Institute and the Psychological Clinic, University of Michigan, Ann Arbor, Mich.

Jeffrey Binder, Ph.D.: Instructor in Psychiatry, Neuropsychiatric Institute; Martin Mayman, Ph.D.: Professor of Psychology, University of Michigan; Steven Dochrman, Ph.D.: NIMH Postdoctoral Fellow (IF02MH53350-01), Psychological Clinic, University of Michigan.

(C) 1974 by Grune \& Stratton, Inc. 
ideal-self discrepancies at either extreme, and taps a tolerance for realistic selfcriticism in the midrange of scores.

In these two studies, the validity of this construct was tested using a scale developed by one of the authors. The sense-of-self inventory developed by Mayman ${ }^{14}$ purports to assess a basic attitudinal predisposition to perceive a certain distance between self and ideal self, regardless of the specific content of the judgments themselves. It reflects a characterologically based response bias rather than a particular self-assessment: "Implicit in this approach is the assumption that answers on each item are not entirely specific for that item; they are dictated in part by certain underlying and rather pre-potent attitudes" (p. 21).

Evidence for the validity of this assumption, regardless of the self-ideal-self format used, was provided by Piotrkowski. ${ }^{15}$ Based on her research with the $Q$-sort format, Piotrkowski concluded that self-ideal-self discrepancy reflects a predisposition to be satisfied or dissatisfied with self. Furthermore, this predisposition is a "generalized set" transcending specific content.

A measure of self-ideal-self discrepancy can be obtained with the sense-of-self inventory by asking subjects to rate themselves on a series of 55 descriptive items that appear ostensibly self-judgmental but actually are relatively neutral with regard to social desirability. Items such as the following are included:

1. I usually try to hide my real self from people.

2. I feel younger than my age.

3. I live according to the motto: "Here today, gone tomorrow."

The ratings are on a five-point ordinal scale, from " +2 " if the subject thinks the description is very true of him to " -2 " if he is sure it is not true of him. The middle point on this scale is "?", if the subject is not sure how to rate himself on that item. Approximately 1 week after the first test, the subjects rated the same items for their "ideal person." Systematic comparisons of a subject's ratings on all items for "self" and for "ideal person" yielded two related scores:

1. Commonality is computed by adding up the total number of items that the subject rated on both " + " or "- " over the two administrations.

2. Divergence is a percentage score equal to the ratio of total number of items that the subject rated with opposite signs over two administrations to the number of unambiguously answered items, i.e., the number of items that are not answered with "?" on either of the two administrations. This score provides a contrasting view of degree of discrepancy and also takes into account interindividual differences in the use of "?".

\section{STUDY 1}

It was hypothesized that self-ideal-self discrepancy is related to a defensive style dimension involving the degree to which an individual can tolerate dissatisfaction with himself. Conceptualized in this way, it is not a direct measure of selfesteem; rather, at either extreme of the continuum, self-ideal-self discrepancy reflects the way in which an individual handles disturbances of self-esteem. At one extreme is the individual who presents himself in the best possible light, as a paragon of admirable qualities. At the other extreme is the individual who in a selfcastigating fashion plays up his weaknesses, pains, and conflicts. If indeed selfideal-self discrepancy is related to such a dimension, then it would be ex- 
pected that a measure of this variable would be strongly related to other measures that assess the same or similar phenomena.

The $K$ scale from the Minnesota Multiphasic Personality Inventory (MMPI) is such a measure. $K$ was developed to assess a test taking attitude appearing either as personal defensiveness (high $K$ ) or as an exaggeration of personal defects and troubles (low $K$ ). ${ }^{16}$ There is evidence that the performance of high and low scorers (reflecting presentation of self in a good light and in a bad light, respectively) is not the result of transitory attiludes, but rather reflects long-standing and deeply ingrained views of self and others. ${ }^{17}$ In this study only the $K$ scale was used-not all of the MMPI. However, no significant attenuation in reliability has been found when the scale is administrated in this way. ${ }^{16}$

An extension of the construct validational test of the defensive implications of self-ideal-self discrepancy is provided if we assume that an inability to tolerate self-dissatisfaction is associated with a tendency to externalize conflict through the use of defense mechanisms, especially denial and projection. Such a defensive style has been experimentally related to a cognitive style dimension involving a predisposition to attend to external rather than internal stimuli, i.e., actual characteristics of one's surroundings rather than thoughts, feelings, and fantasies. ${ }^{18.19}$ The externalizer tends to deploy attention cathexes outward. On the other hand, the individual who plays up his faults and problems tends to internalize his conflicts through the use of other defense mechanisms including intellectualization, isolation, and preoccupation with fantasy. The internalizer tends to deploy attention cathexes inward.

It would be expected that if self-ideal-self discrepancy were related to the manner in which faults and conflicts are externalized or internalized, then it should be strongly related to the direction in which attention cathexes are generally deployed by an individual. In addition, since it is hypothesized that there is a significant overlap in the phenomena tapped by self-ideal-self discrepancy and $K$, it would be expected that $K$ also is related to the direction in which attention cathexes are characteristically deployed.

The cognitive style dimension, "direction of attention-cathexis deployment," was assessed with Bush's reality-attentiveness-reality-inattentiveness (RA-RI) questionnaire. ${ }^{19} \mathrm{~A}$ high RA-RI score indicates predominant internal attention deployment and a low score indicates predominant external attention deployment. Bush found significant relationships in the predicted direction between the RA-RI questionnaire and several behavioral indices of attention deployment. ${ }^{19}$

An underlying assumption throughout this discussion is that within the personality structure defensive and nondefensive adaptive ego functions are intermeshed in a way that allows each to foster the functioning of the others. ${ }^{19}$ Using this assumption it is possible to present a set of hypotheses specifying dynamically how the variables presented above would tend to interact with one another.

It was hypothesized that low self-ideal-self discrepancy is positively related to defensive presentation of self in a good light (high $K$ ) and to a predilection for an externalizing style of attention deployment (low RA-RI). A low self-ideal-self discrepancy is assumed to reflect a tendency to defensively idealize the experienced self in order to avoid inner conflict. Such a tendency would be associated with an 
Table 1. Intercorrelations among Measures of Self-Ideal-Self Discrepancy, Defensive Self-presentation and Direction of Attention Deployment for Total Sample of Study 1

\begin{tabular}{lcrr}
\hline & Divergence \% & $\kappa$ & \multicolumn{1}{c}{ RA-RI } \\
\hline 1. Commonality & $-0.70^{*}$ & $0.27 \dagger$ & $-0.31 \ddagger$ \\
2. Divergence \% & & -0.11 & $0.30 \dagger$ \\
3. $K$ & & & $-0.25 \dagger$ \\
4. RA-RI & & & \\
\hline
\end{tabular}

${ }^{*} p<0.001 ; \dagger p<0.05 ; \ddagger p<0.01$.

attempted good presentation of self. Furthermore, a predilection for external attention deployment, corresponding to a general lack of being tuned-in to the intrapsychic world, would mesh with the attempt to bias the experienced self toward the ideal. The less one knows about oneself the less information is available to contradict the idealized self; on the other hand, a vigilant scanning of the external world helps to avoid situations that can endanger this self-idealization.

It is also hypothesized that high self-ideal-self discrepancy is positively related to defensive presentation of self in a bad light and to a predilection for directing attention cathexes inward. High self-ideal-self discrepancy is assumed to reflect a tendency to cope with conflict paradoxically by accentuating one's faults. Self-depreciation is facilitated by a tendency for introspection. On the other hand, a predilection for self-depreciation will drive the person inward, searching for more evidence for his self-castigations.

\section{METHOD}

\section{Subjects}

This study tested 66 college students at a midwestern university: 35 females and 31 males. Their ages ranged from 18 to 29 , with a median age of 19 . All subjects were drawn from introductory psychology courses, and they participated to fulfill course requirements.

\section{Procedure}

Each subject came to two testing sessions approximately 1 week apart. All tests were groupadministered, with group sizes averaging about 30 . The "self " portion of the sense-of-self inventory and the RA-RI questionnaire and $K$ scale were administered in the first session. The "ideal person" portion of the sense-of-self inventory was administered in the second session. It was emphasized that the data for both testing sessions were essential. Individual subject anonymity was stressed, and a coding system was devised that allowed all of a subject's tests to be identified by number rather than by name.

\section{RESULTS}

Table 1 presents the intercorrelations among measures for the total sample. All predicted relationships but one were confirmed. The one exception is the relationship between divergence percentage and $K$. A breakdown by sex revealed that the relationship holds for females ( 0.05 level of significance), but not for males. Further analysis indicated that for this sample and with these measures, $K$ tended to work better with females than with males.*

\footnotetext{
*An analysis by sex of the intercorrelations was not presented, because except for the relationship described above there were no significant differences between male and femalc pcrformances.
} 


\section{STUDY 2}

The first study tested the hypothesis that self-ideal-self discrepancy is related to the tendency to maximize or minimize self-dissatisfaction. The present study represents a partial replication and an extension of those findings, with a markedly different population in a very different setting. Complete MMPIs were available from a study assessing a rehabilitation program with misdemeanants. ${ }^{*}$ Certain MMPI scales, $K$ being one, are almost always elevated with persons who cannot tolerate the recognition in themselves of faults, weaknesses, or conflicts. Certain other scales are almost always elevated with persons who play up their self-dissatisfactions. If these scales were related to self-ideal-self discrepancy in the predicted directions, it would provide further support for the hypotheses presented in Study 1. Two validity scales $(L$ and $K$ ) and a special scale assessing denial of symptoms $(D n)^{20} \dagger$ measure attempts to present oneself in a good or in a bad light. High scores reflect a predilection to deny anything about self that is felt to be "bad"; low scores reflect a predilection to expose faults, weaknesses, and "bad" thoughts and feelings. It is hypothesized that high scores on these scales are positively related to low self-ideal-self discrepancy.

One validity scale $(F)$ assesses a tendency for unusual responses. In the absence of illiteracy or random responding, high scores are assumed to reflect a conscious accentuation of uncomfortable and disturbing experiences. It is hypothesized that high $F$ is positively related to high self-ideal-self discrepancy.

Four clinical scales $(P t, D, S c, S i)$ assess a tendency to experience oneself as beset with weaknesses, faults, and problems. Individuals scoring high on these scales tend to be burdened with worries, self-castigation, and a general dysphoria. It is hypothesized that high scores on these scales are positively related to high self-ideal-self discrepancy.

\section{METHOD}

\section{Subjects}

Data were available on 41 subjects: 11 females and 30 males. The mean number of grades completed was 11.6 , with $22 \%$ having at least 1 year of college. Many of them were either unemployed or engaged in relatively menial work. Many were without stable living arrangements and slept where they could. All of them had been convicted of misdemeanors in one of the local district courts. They were referred to the rehabilitation project because they were repeat offenders or, if it was a first offense, they were judged to be potential repeaters. The age range was limited to young adults between 17 and 25 years of age. The mean age was 20 .

\section{Procedure}

Each subject came to two testing sessions approximately 1 week apart. All tests were administered individually and were part of a more extensive evaluation. This evaluation included other measures and at least one interview with a social worker. Subjects were ordered by the courts to these sessions, and they felt their performances might have an important bearing on the disposition of their cases. Consequently, they often came with an admixture of apprehension, suspicion, and resentment. The interviews were

*A replication of the RA-RI relationships was impossible because of time limits on the data collection with this sample. One reason for Study 2 was that, unfortunately, complete MMPIs were not available on Study 1 subjects.

†Descriptions of the personality characteristics underlying the MMPI scales were based on the descriptions in Dahlstrom and Welsh, ${ }^{16}$ Butcher, ${ }^{21}$ and the investigators' experiences. 
conducted before any testing was done in order to explain that individual data would not be transmitted to the court and to provide an opportunity for the development of some initial rapport. It is obvious that subjects and setting were vastly different from those in Study 1.

\section{RESULTS}

Table 2 presents the intercorrelations among measures for the total sample. All predicted relationships except one were confirmed. An analysis of these relationships by sex revealed no significant differences. It is noteworthy that results were this good, given the makeup of the sample. The individuals in this sample were required by the courts to take a battery of psychological tests, which the subjects generally assumed would affect the dispositions of their cases. Consequently, they were often uncooperative and universally defensive. However, rather than scrving to invalidate the findings, their defensiveness may have helped to maximize the findings by accentuating the defensive style being studied.

The one relationship not supported was between $L$ and the two scores for selfideal-self discrepancy. The major difference between $L$ and the other MMPI scales, particularly $K$, is its lack of subtlety. In this sample (as with the original Minnesota norms) scores tended to cluster at the lower end of the scale, which indicates a lack of differentiating power. It may be that $L$ is too crude a measure to systematically relate to the complex defensive processes being studied.

A criticism that could be raised in using both $K$ and $D n$ to test the same hypothesis is that there is some item overlap between these two subscales. In fact, in this study they correlated 0.78 . Since in Study $1, K$ correlated with self-idealself discrepancy, it could be argued that the relationship between $D n$ and selfideal-self discrepancy reflects a specific tendency to dissimulate on personality tests rather than a more encompassing characterological proclivity to deny psychological troubles and symptoms. In order to test this hypothesis, a partial correlation was computed between $D n$ and the two scores for self-ideal-self discrepancy, with $K$ held constant. The correlations between $D n$ and commonality and divergence percentage were 0.30 and -0.30 , respectively, significant at the $p<0.10$ level of confidence. It appears that dissimulation is an important factor in denial of symptoms, but it does not account for all of the variance.

Table 2. Intercorrelations between Self-Ideal-Self Discrepancy Scores and MMPI Subscales for Total Sample of Study 2

\begin{tabular}{lcc}
\hline & Commonality & Divergence \% \\
\hline Divergence \% & $-.69^{*}$ & \\
$K$ & -.06 & -.15 \\
$D n$ & $.42 \dagger$ & $-.58^{*}$ \\
$F$ & $.54 \ddagger$ & $-.65^{*}$ \\
$D$ & $-.47 \ddagger$ & $.52 \ddagger$ \\
$P t$ & $-.63^{*}$ & $.47 \ddagger$ \\
$S c$ & -.33 & $.46 \ddagger$ \\
$S i$ & $-.46 \ddagger$ & $.42 \dagger$ \\
\hline
\end{tabular}

${ }^{*} p<0.001 ; \dagger p<0.05 ; \ddagger \rho<0.01$. 


\section{GENERAL DISCUSSION}

The results of the two studies reported here support the hypothesis that selfideal-self discrepancy, rather than assessing adjustment along a normal-abnormal continuum, assesses a defensive style involving the manner in which selfdissatisfaction is either avoided or dwelled upon.

On the one side is the individual who cannot tolerate the internal stress associated with the recognition of undesirable aspects of self. He cannot tolerate experiencing lowered self-esteem; he must create an illusory harmony with his ego ideal. This is reflected in a low tolerance for self-ideal-self discrepancy. This individual will place the highest priority on accumulating evidence of his worthiness, adequacy, and loveableness. Furthermore, he will use such defenses as denial and projection to protect himself from evidence to the contrary. On the other side is the individual who tolerates and even magnifies the internal stress associated with problems of experienced low self-esteem. This individual is persistently at odds with his ego ideal. This is reflected in a high tolerance for self-ideal-self discrepancy. This individual will search inside and outside for evidence of his inadequacy and worthlessness. Furthermore, he will use such defenses as intellectualization and isolation to help him face the discomfort of such an unpleasant, selfdestructive search.

This conceptualization can be related to a distinction made between the ongoing assessment of one's general functioning and more basic, enduring feelings about oncsclf. ${ }^{15}$ The former process involves realistic self-assessment, while the latter process involves a conflict-determined level of self-esteem. When disturbances of self-esteem occur, defensive processes are called into play to handle the disturbances. These defensive processes are characterized by the attitudinal predispositions that we have hypothesized are measured by self-ideal-self discrepancy. Either extreme of self-ideal-self discrepancy is related to a defensive predisposition to be exaggeratedly satisfied or dissatisfied with self. When an individual is defensively locked into either one of these predispositions, his ability to assess realistically his ongoing performance is impaired. The ego flexibility necessary for realistic self-assessment can only exist in the absence of rigidly defensive attitudinal predispositions about self. This state is reflected by the middle range of selfideal-self discrepancy.

This formulation has important implications for the use of self-ideal-self discrepancy as a measure in psychotherapy outcome research. Clinical researchers who use this measure to assess success in psychotherapy may actually be assessing a more specific variable, namely shifts in defensive style. However, this is not to say that self-ideal-self discrepancy cannot serve as an assessment of therapeutic success. If it is assumed that the middle range of self-ideal-self discrepancy is related to a state of ego flexibility optimal for realistic self-assessment, then therapeutic success for an individual could be gauged by using degree of self-ideal-self discrepancy at the beginning of therapy as a reference point and measuring from that point degree and direction of change in discrepancy as a function of therapy. For example, if an individual began psychotherapy with a large self-ideal-self discrepancy and during the course of therapy this discrepancy decreased to a middle range, then it could be argued that therapy was a success. However, if someone 
began therapy with very little self-ideal-self discrepancy and during the course of therapy there was no increase in the discrepancy (of if there was a further decrease), then it could be argued that therapy did not successfully deal with a rigidly defensive predisposition to avoid any dissatisfaction with self (this type of individual usually comes into therapy with the fantasy that his troubles are caused by others or by some irritant that really has no significant implications for him as a person).

Construct validity for interpreting measures of self-ideal-self discrepancy as related to a particular defensive stylc has becn demonstrated. The mcasurc uscd in this report, the sense-of-self inventory, has proved to be a useful research tool. It is easy and quick to administer. In addition, item content is relatively neutral, so an individual does not feel himself to be under close scrutiny, which should cut down defensiveness. By designing the scale so that the content of individual items is essentially irrelevant, the evidence for self-ideal-self discrepancy assessing a relatively content-free attitudinal predisposition is directly taken into consideration. ${ }^{15}$ It is hoped that further validational research will establish the generality of the variable which we suggest plays a significant part in measures of self-ideal-self discrepancy.

\section{REFERENCES}

1. Butler J, Haigh G: Changes in relation between self concepts and ideal concepts consequent upon client-centered counseling, in Rogers CR, Dymond RF (eds): Psychotherapy and Personality Change: Coordinated Studies in the Client-Centered Approach. Chicago, University of Chicago Press, 1954

2. Bills R, Vance E, McLean O: An index of adjustment and values. $\mathrm{J}$ Consult $\mathrm{Clin}$ Psychol 15:257-261, 1951

3. Bills R: Rorschach characteristics of persons scoring high and low on acceptance of self. J Consult Clin Psychol 17:36-39, 1953

4. Chase P: Self concepts in adjusted and maladjusted hospital patients. J Consult Clin Psychol 21:495-497, 1957

5. Turner R, Vanderlippe R: Self-ideal congruence as an index of adjustment. J Abnorm Soc Psychol 57:202-206, 1958

6. Satz $\mathrm{R}$, Baroff $\mathrm{A}$ : Changes in the relation between self-concepts and ideal-concepts of psychotics consequent upon therapy. J Gen Psychol 67:291-297, 1962

7. Butler J: Self-ideal congruence in psychotherapy. Psychotherapy: Theory Research Practice 5:13-17, 1968

8. Chodorkoff G: Adjustment and discrepancy between the perceived and the ideal self. J Clin Psychol 10:266-267, 1954

9. Friedman I: Phenomenal, ideal, and pro- jected conceptions of self, $\mathrm{J}$ Abnorm Soc Psychol $51: 611-615,1955$

10. Rogers A: The self concept in paranoid schizophrenia. J Clin Psychol 14:365-366, 1958

11. Ibelle B: Discrepancies between self-concepts and ideal self-concepts in paranoid schizophrenics and normals. Unpublished doctoral dissertation, University of Chicago, 1961

12. Block $J$, Thomas $H$ : Is satisfaction with self a measure of adjustment? J Abnorm Soc Psychol 51:254-259, 1955

13. Altrocchi J, Parsons O, Dickoff $\mathrm{H}$ : Changes in self-ideal discrepancy in repressors and sensitizers. J Abnorm Soc Psychol 61:6772. 1960

14. Mayman M: A study of the sense of self. Unpublished doctoral dissertation, University of Kansas, 1953

15. Piotrkowski K: An investigation into the self-ideal correlation. Unpublished research paper, 1972

16. Dahlstrom W, Welsh G: An MMPI Handbook. Minneapolis, University of Minnesota Press, 1960

17. Collier J: Some factors influencing answers on the multiphasic $\mathrm{K}$ scale. Unpublished doctoral dissertation, University of Minnesota, 1946

18. Voth H, Mayman M: The psychotherapy process and its relation to ego-closeness-egodistance: Part I. J Nerv Ment Dis 143:324-337, 1966 
19. Bush M, Hatcher R, Mayman M: Reality attentiveness-inattentiveness and externalization-internalization in defensive style. $\mathrm{J}$ Consult Clin Psychol 33:343-350, 1968

20. Little R, Fisher J: Two new experimental scales of the MMPI. J Consult Psychol 22:305306, 1958

21. Butcher J (ed): MMPI: Research Developments and Clinical Applications. New York, McGraw-Hill, 1969 